\title{
Temporomandibular joint replacement devices - dark past to challenging future
}

\author{
Louis G. Mercuri ${ }^{1,2}$ \\ 'Department of Orthopaedic Surgery, Rush University Medical Center, Chicago, IL 60612, USA. \\ ${ }^{2}$ Clinical Consultant, TMJ Concepts, Ventura, CA 93003, USA. \\ Correspondence to: Prof. Louis G. Mercuri, Clinical Consultant, TMJ Concepts, 2233 Knoll Dr., Ventura, CA 93003, USA. \\ E-mail: Igm@tmjconcepts.com
}

How to cite this article: Mercuri LG. Temporomandibular joint replacement devices - dark past to challenging future. Stomatological Dis Sci2019;3:3. http://dx.doi.org/10.20517/2573-0002.2018.25

Received: 2 Nov 2018 First Decision: 8 Jan 2019 Revised: 29 Jan 2019 Accepted: 29 Jan 2019 Published: 25 Feb 2019

Science Editors: Raúl González-García Copy Editor: Cai-Hong Wang Production Editor: Huan-Liang Wu

\begin{abstract}
Alfred Stille said, "Medicine, like all knowledge has a past as well as a present and a future...in that past is the soil out of which improvement must grow." This original paper will review how past successes and failures have led to the development of improved temporomandibular joint replacement devices. Future considerations and challenges will be presented.
\end{abstract}

Keywords: Temporomandibular joint, TMJ, alloplastic joint replacement

\section{INTRODUCTION}

Alfred Stille said, "Medicine, like all knowledge has a past as well as a present and a future...in that past is the soil out of which improvement must grow." ${ }^{,[1]}$. This review will discuss how past successes and failures have led to the development of improved temporomandibular joint (TMJ) replacement devices. Future considerations and challenges will be presented.

\section{HISTORY OF TMJ REPLACEMENT}

In 1840, Carnochan ${ }^{[2]}$, a New York surgeon, was credited with the idea of interposing material between the surfaces of a joint. He attempted to mobilize a patient's ankylosed jaw by placing a small block of wood

\footnotetext{
(c) (7) (c) The Author(s) 2019. Open Access This article is licensed under a Creative Commons Attribution 4.0 International License (https://creativecommons.org/licenses/by/4.0/), which permits unrestricted use, sharing, adaptation, distribution and reproduction in any medium or format, for any purpose, even commercially, as long as you give appropriate credit to the original author(s) and the source, provide a link to the Creative Commons license, and indicate if changes were made.
}

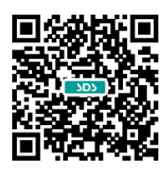




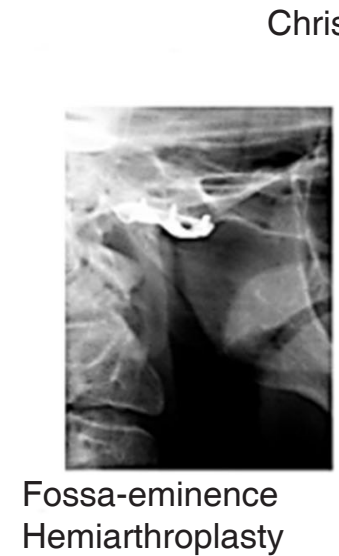

Christensen devices

Hemiarthroplasty

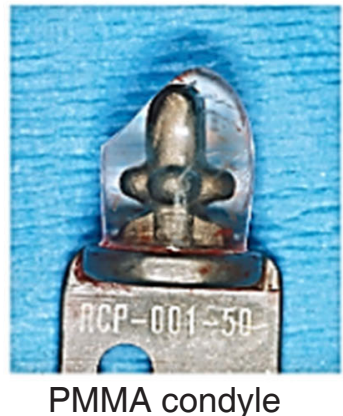

Figure 1. Christensen devices

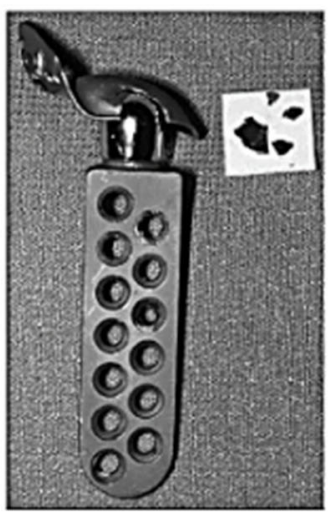

Metal-metal

between the raw bony surfaces after resection at the condylar neck.

Over the past 120-plus years, partial or total TMJ reconstruction cases were primarily performed for the management of ankylosis, reconstruction of mandibular function and form after ablative tumor surgery, trauma, and arthritic disease. However, in the literature these cases were presented as small series or single case reports with poor or no follow-up.

In the 1960's Christensen reported resurfacing of the glenoid fossa with a thin cast vitallium fossa-eminence hemiarthroplasty prosthesis for the management of TMJ ankylosis ${ }^{[3]}$. As a result of the bony condylar changes seen with the fossa-eminence device, in the early 1990's Christensen developed a cast vitallium ramus-condyle component with a polymethylmethacrylate condyle to create a total joint prosthesis ${ }^{[4]}$. However, due to wear under functional loading, this bearing surface geometry was soon abandoned to be replaced by a metal-on-metal bearing surface device ${ }^{[5]}$. None of these devices are presently available to surgeons [Figure 1].

In the late 1970's, the interpositional TMJ implant was developed. It was a laminate of either vitreous carbon (Proplast I), aluminum oxide (Proplast II), or synthetic hydroxyapatite (Proplast HA) and polytetrafluoroethylene [PTFE] (Teflon) ${ }^{[6]}$.

The Proplast component was designed to be placed against the fossa temporal bone to encourage the ingrowth of tissue to stabilize the implant. The smooth Teflon portion was designed to function against the condyle.

Despite evidence published a decade earlier by Charnley ${ }^{[7]}$, Scales and Stinson ${ }^{[8]}$ that Teflon under functional loading underwent fragmentation resulting in foreign body giant cell reactions in the hip, the developers and the FDA did not feel that the TMJ was a loaded joint, therefore, this device would not fragment, so the device received approval.

As the need for a total alloplastic TMJ replacement system grew because of the material failure of ProplastTeflon, reports surfaced in the literature related to the development, utilization and successful outcomes of these devices.

In 1995 Mercuri et al. ${ }^{[9]}$ reported on preliminary results with the use of a patient-fitted or custom CAD/ CAM total TMJ replacement system (TMJ Concepts, Ventura, CA) [Figure 2]. In 2000, Quinn ${ }^{[10]}$ introduced 


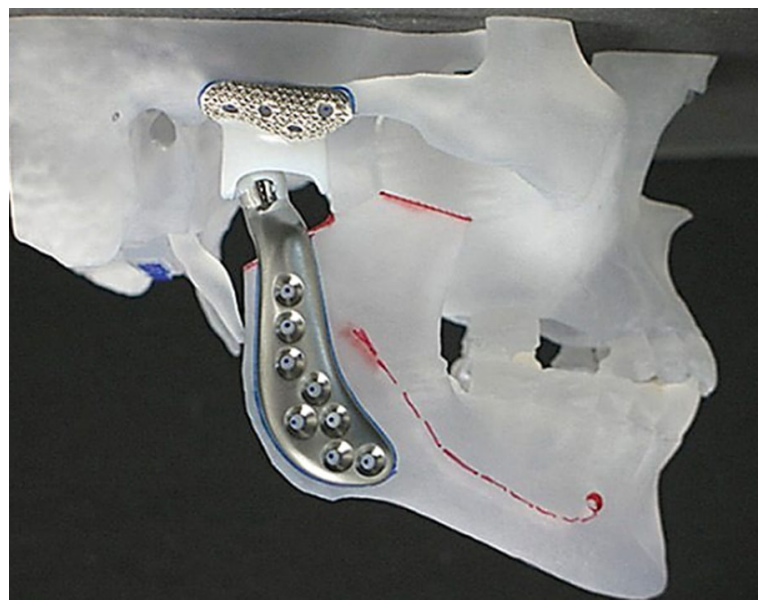

Figure 2. TMJ concepts patient-fitted TMJ replacement

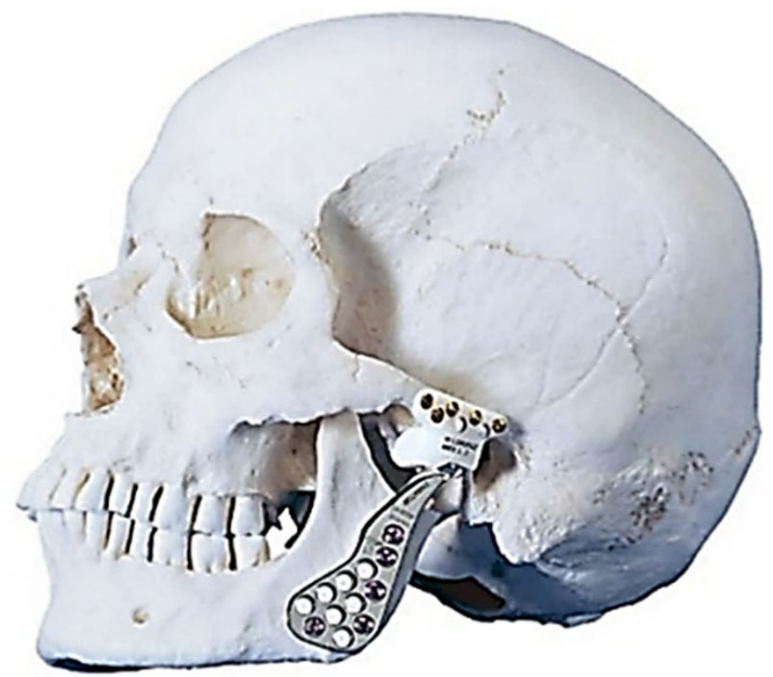

Figure 3. Zimmer biomet stock TMJ replacement

a stock TMJ replacement device (Zimmer Biomet, Jacksonville, FL) [Figure 3]. Both of these systems were approved by the FDA. Both are made using materials successfully employed in orthopedic joint replacement devices for decades. Zimmer Biomet also manufactures a custom TMJ replacement device only available outside the US since it is not yet FDA approved.

The results of long-term follow-up studies support the surgical implantation of both stock and custom TMJ replacement systems ${ }^{[11,12]}$. Further, these studies demonstrate that TMJ replacement is safe and effective, reduces pain, improves mandibular function, and patients' quality of life, with few complications. Therefore, TMJ replacement represents a viable and stable long-term solution for cranio-mandibular reconstruction in patients with irreversible end-stage TMJ disease.

\section{FUTURE CONSIDERATIONS AND CHALLENGES}

\section{Utilization and costs}

A recent study found at least 15 countries that will potentially generate 21 different devices (6 Stock, 15 custom). It appears that the major impetus for this proliferation of TMJ replacement devices appears to 
be costly. Until recently, TMJ Concepts and Zimmer Biomet have enjoyed the major market share worldwide. However, the cost of doing business in each country, lack of or restrictive healthcare coverage, have contributed to the final cost to the hospital and/or the patient for both systems. Therefore, producing TMJ replacement devices within a country, rather than importing them, has become a very attractive alternative $e^{[13]}$.

The introduction of virtual surgical case planning, as well as the advent and supposed ease of metal 3D printing have provided further momentum to this growing phenomenon. Many of the aforementioned 21 devices will be or are being manufactured using direct metal laser sintering technology, despite its potential drawbacks, especially porosity potentially resulting in component failure under functional stresses.

Surgeons, hospitals and healthcare management organizations are being convinced by local manufacturers that these computer-based design and manufacturing processes will not only result in lower TMJ replacement device costs, but also decrease design, manufacturing and delivery delays.

In the future, TMJ replacement will never approach the numbers anticipated for orthopaedic hip and knee replacements. Mimicking an orthopaedic study that projected the number of hips and knees that will require replacement and/or revision in $2030(174 \% \text { and } 673 \% \text { increases respectively })^{[14]}$. Using the same statistical metrics, it was demonstrated that the probable need for TMJR devices by 2030 would be exponentially less $(<50 \% \text { increase })^{[15]}$. Therefore, the supply of TMJ replacement devices will surpass the future demand.

\section{Surgeon interest, education and competency}

While it is not reasonable to expect every graduate of an oral and maxillofacial surgery residency to have an interest in every aspect of the specialty, those with an interest in the management of temporomandibular joint disorders should be provided with some exposure and experience with non-invasive as well as invasive TMJ management options during training. Development of TMJ fellowships should be considered for those interested in developing competency in this area of the specially ${ }^{[16-18]}$.

\section{Improved embodiment (materials and design)}

Tissue engineering may hold promise for TMJ replacement in the future, but many regulatory, laboratory and clinical issues are still to be resolved.

Salash et al ${ }^{[19]}$ proposed the following indications and contraindications for tissue engineered TMJ replacement: Indications - irreparable condylar trauma, developmental or acquired TMJ pathology in skeletally immature patients, condylar hyperplasia and documented metal hypersensitivity. Contraindications - patients with unresolved parafunctional oral habits, persistent local infection, ankylosis, end-stage systemic diseases (e.g., high inflammatory arthritic diseases), multiply operated patients, previous exposure to failed alloplastic devices.

All TMJ replacement devices are not created equal. Failure of any implanted device may be due to one of a number of causes, including failure of concept, failure of embodiment, failure of implantation technique or limitations of technology ${ }^{[20]}$. Therefore, it is important in the development of future TMJR devices, that they are based on sound biologic and physiologic principles, constructed of biocompatible materials with mechanical properties that are fatigue, wear and static tested under appropriate functional loads, implanted properly and aseptically in the right patients for the right diagnosis.

\section{Increasing antibiotic resistant organisms}

Antibiotic resistance is one of the greatest global threats. This phenomenon was recognized after antibiotics were first introduced, however, its impact was initially moderated with the development and use of newer 
agents. However, very few new classes of antibiotics have been developed since the late 1960s. Some organisms, particularly Gram-negative bacteria have extremely limited therapeutic options ${ }^{[21]}$.

Antibiotic resistance is an international concern. Broadly, interventions can be categorized into two main approaches. Firstly, there are strategies aimed at protecting the existing antibiotics and preventing the emergence and spread of further resistance. Secondly, there are strategies aimed at reinvigorating drug development and bringing new antibiotics to market. Alternatives to current antibiotic therapy also need to be assessed, either through the development of new drug classes or through the use of vaccines or other therapeutic strategies ${ }^{[22]}$.

Identifying recipient risk factors, adopting a proper surgical technique, appropriate wound care, optimizing the operating room environment, and appropriate postoperative care have become some of the core elements that can help to minimize the overall incidence of this complication ${ }^{[23]}$.

\section{Ability to differentiate septic from aseptic cases}

Late-onset chronic (low-grade) periprosthetic joint infections are often accompanied by unspecific symptoms, false-negative cultures or nonspecific low values of serum biomarkers. This may lead to the unintended implantation of a revision prosthesis into an infected surgical site with the risk of short-term failure developing again. Conversely, false diagnosis of joint infection may result in multistage revision procedures, which expose the patient to unnecessary surgical procedures and inappropriate antibiotic treatment. Ettinger et al. ${ }^{[24]}$ demonstrated that circulating biomarkers IL- 6 and CRP can be measured preoperatively to distinguish between aseptic prosthesis loosening and low-grade joint infection.

\section{Increased exposure to metals in the environment}

Heavy metal toxicity has proven to be a major threat and there are several health risks associated with it. The toxic effects of these metals, even though they do not have any biological role, remain present in some or the other form harmful for the human body and its proper functioning. They sometimes act as a pseudo element of the body while at certain times they may even interfere with metabolic processes. Few metals, such as aluminum, can be removed through elimination activities, while some metals get accumulated in the body and food chain, exhibiting a chronic nature. Various public health measures have been undertaken to control, prevent and treat metal toxicity occurring at various levels, such as occupational exposure, accidents and environmental factors. Metal toxicity depends upon the absorbed dose, the route of exposure and duration of exposure, i.e., acute or chronic. This can lead to various disorders and can also result in excessive damage due to oxidative stress induced by free radical formation ${ }^{[25]}$.

\section{CONCLUSION}

Despite past conceptual and embodiment failures, recent advancements in material science and understanding of joint mechanics, make TMJ replacement a safe and effective tool for the management of end-stage TMJ pathology. The practice of modern oral and maxillofacial surgery should be impossible without these devices, but we must continue to seek improvements in designs and materials in the future.

"The arrogance of success is to think that what you did yesterday will be sufficient for tomorrow." C. William Pollard.

\section{DECLARATIONS}

\section{Authors' contributions}

Mercuri LG solely contributed to this study. 


\section{Availability of data and materials}

Not applicable.

\section{Financial support and sponsorship}

None.

\section{Conflicts of interest}

Louis G. Mercuri - compensated Clinical Consultant and shareholder in TMJ Concepts, Ventura, CA.

\section{Ethical approval and consent to participate}

Not applicable.

\section{Consent for publication}

Not applicable.

\section{Copyright}

(c) The Author(s) 2019.

\section{REFERENCES}

1. Stille A. American Medical Biographies. In: Kelly HA, Burrage WL, editors. Baltimore: The Norman, Remington Co.; 1920.

2. Carnochan JM. Mobilizing a patient's ankylosed jaw by placing a block of wood between the raw bony surfaces after resection. Arch de Med 1860;284.

3. Christensen RW. The correction of mandibular ankylosis by arthroplasty and insertion of a cast vitallium glenoid fossa. Am J Orthop 1963;48:16-24.

4. Christensen RW. Arthroplastic Implantation of the TMJ. In: Thomas CC, editor. Oral Implantology. Springfield, IL; 1970. pp. 284-98.

5. Saha S, Campbell CE, Sarma A, Saha S, Christensen RW. A biomechanical evaluation of the Christensen temporomandibular joint implant. Crit Rev Biomed Eng 2000;28:399-403.

6. Homsy CA, Cain TE, Kessler FB, Anderson MS, King JW. Porous implant systems for prosthesis stabilization. Clin Orthoped 1972;89:22-35.

7. Charnley J. Tissue reactions to polytetrafluoroethylene. Lancet 1963;2:1379.

8. Scales JT, Stinson NE. Tissue reactions to polytetrafluorethylene. Lancet 1964;283:169.

9. Mercuri LG, Wolford LM, Sanders B, White RD, Hurder A, et al. Custom CAD/CAM total temporomandibular joint reconstruction system: preliminary multicenter report. J Oral Maxillofac Surg 1995;53:106-15.

10. Quinn PD. Lorenz prosthesis. In: Donlon WC, editor. Total temporomandibular joint reconstruction. Oral and Maxillofac Surg Clin N Am 2000;12:93-104.

11. Wolford LM, Mercuri LG, Schneiderman ED, Movahed R, Allen W. Twenty-year follow-up study on a patient-fitted temporomandibular joint prosthesis: the Techmedica/TMJ concepts device. J Oral Maxillofac Surg 2015;73:952-60.

12. Leandro LF, Ono HY, Loureiro CC, Marinho K, Guevara HA. A ten-year experience and follow-up of three hundred patients fitted with the Biomet/Lorenz Microfixation TMJ replacement system. Int J Oral Maxillofac Surg 2013;42:1007-13.

13. Ellege ROC, Mercuri LG, Attard A, Green J, Speculand B. Temporomandibular joint total joint replacement (TMJR) systems: a global overview. Manuscript in review. Br J Oral and Maxillofac Surg. Forthcoming 2019.

14. Kurtz S, Ong K, Lau E, Mowat F, Halpern M. Projections of primary and revision hip and knee arthroplasty in the United States from 2005 to 2030. J Bone Joint Surg Am 2007;89:780-5.

15. Onoriobe U, Miloro M, Sukotjo C, Mercuri LG, Lotesto A, et al. How many temporomandibular joint total joint replacements will be performed in the United States by 2030? J Oral Maxillofac Surg 2016;74:1531-38.

16. Lotesto A, Miloro M, Mercuri LG, Sukotjo C. Are oral and maxillofacial surgery residents trained adequately in alloplastic total temporomandibular joint replacement? J Oral Maxillofac Surg 2016;74:712-8.

17. Mercuri LG. Temporomandibular Joint Disorder Management in Oral and Maxillofacial Surgery. J Oral Maxillofac Surg 2017;75:927-30.

18. Momin M, Miloro M, Mercuri LG, Munaretto A, Markiewicz MR. Survey of senior oral and maxillofacial surgery resident confidence in performing invasive temporomandibular joint procedures. J Oral Maxillofac Surg 2017;75:2091.e1-10.

19. Salash JR, Hossameldin RH, Almarza AJ, Chou JC, McCain JP, et al. Potential indications for tissue engineering in TMJ surgery. J Oral Maxillofac Surg 2016;74:705-11.

20. Schmalzried TP, Brown IC. Mechanisms of prosthetic joint failure. In: Galante JO, Rosenberg AG, Callaghan JJ, editors. Total hip revision surgery. New York: Raven Press; 1995. pp. 322-31.

21. Sabtu N, Enoch DA, Brown NM. Antibiotic resistance: what, why, where, when and how? Br Med Bull 2015;116:105-13.

22. Spellberg B, Bartlett JG, Gilbert DN. The future of antibiotics and resistance. N Engl J Med 2013;368:299-302. 
23. Mercuri LG. Prevention and detection of prosthetic temporomandibular joint infections - update. Int J Oral Maxillofac Surg 2019;48:217-24.

24. Ettinger M, Calliess T, Kielstein JT, Sibai J, Brückner T, et al. Circulating biomarkers for discrimination between aseptic joint failure, lowgrade infection, and high-grade septic failure. Clin Infect Dis 2015;61:332-41.

25. Jaishankar M, Tseten T, Anbalagan N, Mathew BB, Beeregowda KN. Toxicity, mechanism and health effects of some heavy metals. Interdiscip Toxicol 2014;7:60-72. 